\title{
La reorganización de la Hispania Citerior bajo Augusto
}

\author{
Pedro LóPez BarJa De Quiroga \\ Universidad de Santiago de Compostela \\ pedro.barjadequiroga@usc.es
}

\section{RESUMEN}

La provincia Transduriana era una provincia romana, no el ámbito de actuación de un legado; Gallaecia et Asturia nunca formaron parte de la provincia Lusitania; el límite oriental de la Transduriana probablemente haya que situarlo en Noega.

Palabras clave: Transduriana. Provincia. Jurisdicción delegada. Gobernador provincial. Gallaecia. Bronce de El Bierzo

\section{The Reorganization of Hispania Citerior under Augustus}

\begin{abstract}
Provincia Transduriana was a Roman province, not the territory assigned to a legate; Gallaecia et Asturia were never integrated within the provincia Lusitania; the oriental border of the Transduriana probably was located at Noega.
\end{abstract}

Key Words: Transduriana. Province. Delegated jurisdiction. Provincial Governor. Gallaecia. Bronze from El Bierzo. 
Nuestro punto de partida necesariamente ha de ser la famosa "restauración de la República" en 28-27 a.C., pues a partir de ese momento, en adelante, Augusto retiene para sí una enorme provincia (Galia, Hispania, Siria), que gobernará mediante legados. Está naciendo una nueva forma de administración imperial, que desafía en el fondo muchos de los usos y tradiciones republicanas, al mismo tiempo que, como consecuencia de las guerras contra cántabros y astures, se está llevando a cabo una reorganización profunda de Hispania. La coincidencia en el tiempo entre ambas transformaciones, la general del imperio y la particular de Hispania, complica sobremanera la solución de los problemas que se plantean para la Hispania Citerior augustea.

\section{El concepto de provincia}

Empecemos por este punto, porque su solución condiciona la forma en que abordaremos los dos restantes. Ha corrido bastante tinta sobre el significado de provincia, en el bronce de El Bierzo, sobre si tiene sentido territorial o si es un "ámbito de competencias", un "mando militar" o algo semejante. ${ }^{1}$ Para aclarar las cosas, conviene recordar lo que dice Richardson en el análisis más exhaustivo que hay sobre esta cuestión: hasta la década de los años 60 a.C., la creación de una provincia había supuesto la designación de un comandante por el Senado; era esencialmente el área en el que se ejercía el imperium y no suponía la "anexión", pues era el territorio que se asignaba a los comandantes, para hacer la guerra, como podía ser Macedonia en la primera mitad del siglo II a.C.: es evidente que en aquellos momentos la "provincia Macedonia" no formaba parte del imperio, pues era un reino independiente. Sin embargo, en época de Augusto la situación ha cambiado: transformar un territorio en una provincia significaba, ya sí, incorporarlo al imperio. ${ }^{2}$ En efecto, el texto de [Caes.] B.Afr. 97.1 es muy significativo: Caesar interim Zamae auctione regia facta bonisque eorum uenditis qui ciues Romani contra populum Romanum arma tulerant, praemiisque Zamensibus qui de rege excludendo consilium ceperant tributis, uectigalibusque regiis irrogatis ex regnoque provincia facta atque ibique Sallustio pro consule cum imperio relicto ipse Zama egressus Uticam se recepit. César transformó el reino de Juba en una provincia y puso a Salustio al frente de ella, como procónsul, cum imperio; aquí, desde luego, el sentido de anexión, de pasar a formar parte del imperio de Roma, es evidente. Algo muy semejante pudo ocurrir en la Transduriana, tras el final de las guerras cántabras. Augusto convirtió el territorio conquistado en provincia y Sestio Quirinal levantó tres aras para marcar con ellas que los romanos habían llegado a los límites de la ecúmene. ${ }^{3}$ En la fecha del bronce de Bembibre, provincia Transduriana no es ya el ámbito en el que se ejerce el imperium del comandante sino una parte reconocida del imperio romano.

\footnotetext{
1 GARCía RiAZa 2011, 38 y n.29 considera que la acepción de provincia como "teatro de operaciones" podría estar aún vigente en el bronce de El Bierzo.

2 Richardson 2008, 143 ss.

3 GRÜNER 2005.
} 
Sin embargo, hay una razón tal vez de mayor peso que la simple cronología: provincia Transduriana no puede en ningún caso referirse al área en el que se ejerce el imperium del magistrado, porque el imperium es de Augusto, nunca de sus enviados, subordinados, etc. que sólo lo tienen por delegación. Dicho de otro modo, si queremos entender provincia como el ámbito que corresponde al imperium (tal y como debemos hacerlo, según Richardson, hasta los años finales de la República), ese ámbito es toda Hispania, Galia y Siria, pues esas son las provinciae de Augusto desde el 27 a.C. Los gobernadores de provincias imperiales no son titulares de la jurisdicción, porque lo es únicamente Augusto. Por lo tanto, si nos restringimos al ámbito, más reducido, de la provincia Transduriana, no hay otra alternativa que concebirla en el mismo sentido que cualquiera otra del imperio romano.

\section{Divisiones provinciales de Hispania. El problema de la jurisdicción delegada}

Una vez rechazamos el texto de Dión Casio, 53.12 .5 (las tres provincias hispanas -Bética, Lusitania y Tarraconense- nacen en 27 a.C.), entramos en un terreno desconocido. Lo cierto es que casi la única certeza que tenemos para el periodo posterior es precisamente la existencia de una provincia Transduriana en el 15 a.C. De hecho, es posible ir aún más lejos: si uno lee los Fasti Hispanienses de G. Alföldy, comprobará rápidamente que de ni uno solo de los gobernadores de época de Augusto allí recogidos se indica cuál era la provincia que gobernaba; las fuentes literarias son vagas e imprecisas y en las inscripciones aparecen sencillamente como legati pro praetore, sin la referencia a Augusto -que, por cierto, es la fórmula tradicional republicana- ${ }^{4}$ o bien, en un caso, legatus Caesaris (Paulo Fabio Máximo). Esto es válido también para el más reciente del que tengo noticia, procedente de Ilunum (El Tolmo de Minateda, Albacete): [Domitius Ahe]nobarbu[s leg. eius], supuestamente gobernador de la Citerior en 9 a.C. ${ }^{5} \mathrm{La}$ atribución de cada legado a una u otra provincia es obra de la historiografía moderna (del propio Alföldy, en buena medida, pero también de otros, claro) y depende a su vez de qué provincias había en cada momento, cosa que no sabemos. Es decir, tenemos unos legati Augusti, por un lado, y por otro una reconstrucción hipotética de cuáles eran las provincias hispanas en cada momento; a partir de aquí, se asignan legados a provincias en lo que es otra nueva hipótesis que se suma a la anterior. Sucede que sólo y exclusivamente de Lucio Sestio Quirinal sabemos con total certeza cuál fue la provincia que gobernó: la Transduriana. Dejando ahora a un lado, evidentemente, las sospechas sobre la falsificación del bronce, a mi juicio completamente infundadas, es el único gobernador provincial para todo el periodo augusteo sobre el cual no deberíamos tener ninguna duda.

4 Koch 1989. La primera vez que aparece para Hispania un leg. Augusti pro pr. es con C. Caetronio Micco, CIL II, 2423, donde se le menciona como legatus Aug. Hisp. Citerioris, pese al hecho de que su magistratura más elevada parece haber sido la de pretor. Dada esta anomalía (que un pretorio gobernase una provincia de rango consular), ALFÖLDY 1969, 70 supone que desempeñó las tareas de gobernador en ausencia del gobernador consular L. Aruntio, entre c. 25 y 33 d.C.

5 Alföldy, 2007. 
El principal argumento en contra, en realidad, el único, es que la Transduriana parece poca provincia para un legado consular, pero es probable que Sestio Quirinal tuviera al menos dos legiones a sus órdenes o tal vez más. No sabemos cómo se hizo el paso del ejército de conquista (siete legiones) al de ocupación (tres legiones) ni en qué momento cada una de ellas abandonó Hispania; sólo sabemos que entre el 19 a.C. y el 10 d.C. salieron cuatro legiones. Cuando Sestio Quirinal se hizo cargo de la provincia es probable que tuviera varias legiones a sus órdenes, y el mandato de transformar un territorio recién conquistado en una provincia romana, con todas las tareas censuales, fiscales, de agrimensura, etc. que estaban implícitas en la conversión de un territorio recientemente anexionado en una provincia romana, para lo que contaba, como digo, con el respaldo militar suficiente. ${ }^{6}$ Esto explica tanto la propia mención de Sestio Quirinal en el bronce como el nombramiento de un consular.

Si nos adentramos en el terreno de las hipótesis e intentamos reconstruir cómo fue cambiando la división provincial, a mi juicio, podemos hacerlo del modo siguiente. De acuerdo con Syme, en el 27 Augusto restablece la bipartición tradicional (Hispania Ulterior/Citerior) y en el 16-13, nacen las tres provincias. ${ }^{7}$ Entre medias, durante el periodo 27-16/13, en particular, durante las guerras cántabras, había sólo dos "ejércitos" en la Citerior, no dos provincias. Debo decir que esto me parece poco probable: mientras Augusto estuvo en Hispania (años 26-25 a.C.), es lógico pensar que Hispania se mantuviese como provincia única, bajo su mando, administrada mediante legados que no tienen un ámbito territorial específico. Lo que ocurrió después es difícil de precisar. Parece claro, como hemos visto, que en el 22 a.C. había una provincia Transduriana; ¿las demás? Aquí hay dos opciones posibles: (a) en el año 22 a.C. había sólo dos provincias, la Transduriana y el resto, con un nombre para esta última que desconocemos, hasta que en el 16-13 a.C. nacieron las tres provincias. (b) en el año 22 se habían rehabilitado las dos provincias (Citerior y Ulterior) que coexistieron con la Transduriana hasta el 16-13. En el 2000 opté por la segunda opción, hoy me mantengo en esta misma idea. Hubo tres provincias entre el año 22 y el 16-13 (Transduriana, Citerior y Ulterior), convertidas luego en tres distintas: Bética, Lusitania y Tarraconense, con cesión de la Bética al Senado.

Tal vez algunos lectores consideren que tanto cambio resulta sospechoso, pero lo cierto es que el régimen provincial nunca gozó de la perfecta inmutabilidad con la que a veces nos lo imaginamos. Además de las consideraciones que hace Estrabón (17.3.25), cuando señala que la organización de las provincias ha sufrido cambios entre la llegada de Augusto al poder y su propia época, recordemos ahora dos casos, ambos republicanos. El primero tuvo lugar en 191 a.C. cuando a Emilio Lépido le correspondió en suerte Sicilia, sucediendo en el cargo a L. Valerio, y el Senado ordenó que Valerio se quedase como propretor et provinciam ita dividere, ut una $a b$ Agrigento ad Paschynum esset, altera a Paschyno Tyndareum (Liv., 36.2.11). Más contundente es lo ocurrido en el 178 a.C., cuando el Senador acordó dividir la Galia Cisalpina en dos provincias: Scipio et Laevinus Galliam in duas divisam provincias sortiti sunt (Liv., 41.8.3). Son decisiones coyunturales, que condujeron, al menos en

6 LÓPEZ BARJa 2000, 33.

7 Syme 1969, 126 y 1970. Cfr. Abascal 2006. 
el caso de la Galia, al surgimiento de provincias nuevas, más efímeras aún que nuestra Transduriana.

En un artículo dedicado a la cultura epigráfica de la Hispania romana (publicado póstumamente), Geza Alföldy, en una breve nota al pie, afirmaba lo siguiente (que por comodidad, traduzco al castellano): "Ambos autores [se refiere a Rodríguez Colmenero y a mí mismo] consideran la Transduriana provincia como una provincia en sentido propio, pero pasan por alto que esta provincia no puede ser otra cosa que el distrito militar que se extiende al norte del Duero, en el cual, según Estrabón (3.4.20 = C 166-167), en época de Augusto, se encontraban dos legiones bajo las órdenes de un legado, que a menudo era de rango consular, el cual estaba subordinado al gobernador de la Hispania Citerior". ${ }^{8}$ Esto no es exactamente lo mismo que había dicho Alföldy en su artículo de ZPE: allí sostuvo que la Transduriana era "una provincia dentro de una provincia", en este caso, dentro de la Ulterior y que Lucio Sestio Quirinal era gobernador de la Ulterior, no de la Transduriana. ${ }^{9}$ Algo semejante sostuvo Diego Santos, aunque complicando un poco las cosas al afirmar que la Transduriana era una diócesis de la Lusitania del mismo modo que en el texto de Estrabón, Gallaecia et Asturia eran una diócesis de la Citerior. ${ }^{10}$ Como es sabido, el texto de Estrabón no habla de diócesis, un término introducido en la historiografía por Mommsen que sólo ha causado confusión. Lo cierto es que ver en Sestio Quirinal al gobernador de la Ulterior, de la Citerior o de la Lusitania va en contra de lo que afirma el bronce de Bembibre, pues no hay ambigüedad en cuanto a que Sestio Quirinal fue gobernador de la Transduriana: Lucio Sestio Quirinale leg(ato) meo eam provinciam optinente se lee en líneas 10-11. Por eso, creo que Alföldy modificó tal vez su postura pensando ahora en L. Sestio Quirinal como un legado de rango consular en la Transduriana, subordinado al gobernador provincial. Mientras que en su artículo en ZPE, Alföldy consideraba a los legados aludidos en el bronce de El Bierzo como vicelegados (para jurisdicción y mando militar), a las órdenes del gobernador provincial y explícitamente los comparaba con procuratores que tenían Asturia et Callaecia o bien el Helesponto como su provincia; ${ }^{11}$ ahora se refiere a los legados consulares tal vez pensando (aunque no lo menciona) en Dion Casio, 53.14 .7 (texto sobre el que volveremos más adelante). En efecto, una vez que Alföldy deja de referir la Transduriana a la Ulterior (como hacía en $Z P E$ ) y pasa a referirla a la Citerior, entra en escena el tan traído y llevado Estrabón, 3.4.20.

La lectura del texto de Estrabón se ha visto oscurecida por la referencia a las diócesis por parte de Mommsen, primero, y luego por los "distritos militares" de Henderson, a los que vuelve a aludir Alföldy en el texto citado supra, cuando habla de la Transduriana como de un "distrito militar". Las diócesis, aunque aceptadas por Albertini, hace tiempo que han desaparecido de la bibliografía especializada. ${ }^{12}$ Los

8 AlFÖLDY 2011, 189 n.12.

9 AlfÖLdy 2000a, 204-205.

10 Diego SAntos 2002. En la p.253, considera a Sestio Quirinal propraetor de la Lusitania, pero en p.254 n.17 lo es de la Citerior Tarraconense.

11 AlFöldy 2000a, 204, remite a 2000, p.14 n.12.

12 Henderson 1942; Albertini 1923, 54. 
distritos militares, en cambio, de alguna manera se mantienen e incluso como vemos se quiere interpretar en este sentido la provincia Transduriana, como una circunscripción militar. Sin embargo, deberían correr la misma suerte que las diócesis, pues para convencerse de que no son distritos militares basta con fijarse en el tercer legado, sin tropas a su cargo y en un territorio tan pacífico que a sus habitantes se les conoce como "togados". ${ }^{13}$

Una lectura rápida del texto permite extraer algunas conclusiones interesantes. Lo primero que debemos señalar es que hay un acuerdo pleno entre el texto de Estrabón y el de Dión Casio, 53.14.7, aunque Dión Casio se refiera exclusivamente a las provincias del Senado y del pueblo romano: "(En las provincias llamadas del pueblo y del Senado...) en cuanto a los asesores (paredreúontes = presbeutái), cada magistrado elegía por sí mismo a los suyos; los pretorios, a uno de su mismo o inferior rango y los consulares, a tres de su mismo rango, sometidos a la aprobación del emperador". Estrabón dice exactamente lo mismo: señala que en la Bética hay un pretor, con un cuestor y un legado, mientras que, en lo que es propiedad del César, "se envían dos legados, uno pretoriano y el otro consular; el pretoriano tiene a su vez otro legado a su cargo para administrar justicia a los lusitanos...; el resto, que es la mayor parte de Iberia, se halla bajo el mando de un gobernador consular que cuenta con un ejército considerable de tres legiones y tres legados" (trad. de Gómez Espelosín). Como regla general, pues, a los gobernadores pretorios les corresponde un legado y a los consulares, tres. La coincidencia es plena, por mucho que la regulación de las provincias del príncipe se hiciera mediante una ley en el 27 a.C. mientras que, de las "del Senado y del pueblo romano", se ocupase una ley distinta y posterior. ${ }^{14}$

Lo segundo que conviene indicar, incidentalmente, es que de estos legados de la Bética y de la Lusitania, que menciona Estrabón, no tenemos noticia epigráfica alguna, pero sin duda existieron: una nueva llamada de atención contra la irresistible tentación de creer que lo que no aparece en una inscripción, no existe. ${ }^{15}$

Lo tercero y más importante: el gobernador mantiene su jurisdicción sobre toda su provincia, la recorre entera en verano y revisa las decisiones de sus legados, porque claramente están sometidos a él, no administran un área independiente dentro de la provincia. Su jurisdicción es delegada y por lo tanto tiene ciertos límites, en concreto, el imperium, que es concedido por ley (¿curiata?), no se puede delegar y por esta razón el legado del gobernador, en principio, no tiene animadversio. Al menos, esto es lo que opina Papiniano, aunque Paulo discrepa de él en este punto (Dig. 1.21.1.1):

\footnotetext{
13 López Barja, 2000, 41-42. En el mismo sentido, Palao 2012, 94.

14 Ferrary, 2001, 109-113.

15 Hay una posible referencia en lex Urs. 127 lín.2, donde se reserva asiento en la orchestra a quive i(ure) $d$ (icundo) p(raerit), lo que Mommsen 1905, 220 consideró que se refería a personas del círculo del gobernador provincial, entre ellas, su legatus (en el mismo sentido, Hardy 1912, 54 n.139); CraWFord 1996, vol. I, 451 considera en cambio que se trata del IIuir o del prefecto, pero todo el capítulo está referido a personas del ordo senatorial, complementando lo establecido en el 125, donde se mencionan los magistrados locales. Menos verosímil considero la opinión de D’Ors 1953, 265, para quien la expresión se ha de entender que alude al pretor en Roma.
} 
Qui mandatam iurisdictionem suscepit, proprium nihil habet, sed eius, qui mandauit, iurisdictione utitur. Verius est enim more maiorum iurisdictionem quidem transferri, sed merum imperium quod lege datur non posse transire: quare nemo dicit animaduersionem legatum proconsulis habere mandata iurisdictione. Paulus notat: et imperium, quod iurisdictioni cohaeret, mandata iurisdictione transire uerius est.

Las decisiones del legado son recurribles ante el gobernador y éste en su caso puede decidir lo que le parezca sobre la injusticia cometida por su legado (Dig. 49.3.2 Ven. Sat.). Esto quiere decir que el legado del gobernador está claramente subordinado a él, que es quien tiene imperium y iurisdictio sobre toda la provincia; no hay un reparto de "funciones" ni de "territorios" entre el gobernador y sus legados, lo que significa que aunque el legado actúe en ámbito territorial concreto (como se ve claramente que sucede en Estrabón, 3.4.20), cabe apelar contra sus decisiones ante el gobernador provincial. Más aún, hay determinados aspectos jurisdiccionales reservados al gobernador, que, por lo tanto, el legado - tal vez por carecer de imperium-no puede hacer, como manumitir esclavos: apud legatum uero proconsulis nemo manumittere potest, quia non habet iurisdictionem talem (Dig. 1.16.2.1 Marciano). También en este caso, como en el anterior, Paulo discrepa, manteniendo una postura más flexible: apud proconsulem, postquam urbe egressus est, uindicta manumittere possumus: sed et apud legatum eius manumittere possumus (Dig. 1.16.5).

Como ya vieron en su día Costabile y Licandro, el bronce de El Bierzo deja muy claro que no se trata de vicelegados, son legados del emperador Augusto que están al frente de una provincia: ${ }^{16}$... legatis meis (y subrayo el meis) qui Transdurianae provinciae praefuerunt (lín.6-8); y, más adelante (lín. 11-12), refiriéndose a Lucio Sestio Quirinal lo califica de leg(ato) meo eam provinciam optinente $\{m\}$. No son legados del gobernador provincial, sino legati Augusti. Y no pueden ser otra cosa, además, porque la jurisdicción delegada no puede delegarse a su vez. Paulo es taxativo, porque en efecto la cuestión no merece más discusión (Dig. 1.21.5pr.): Mandatam sibi iurisdictionem mandare alteri non posse manifestum est. Aquí es donde nos encontramos con un problema grave. Si la jurisdicción delegada no puede delegarse a su vez, ¿quiénes son estos legados del gobernador de la Citerior o de la Lusitania? La solución que propone Fanizza es probablemente la más sencilla, aunque carece de apoyo textual sólido: ${ }^{17}$ con Augusto se delegó la institución, no el cargo, se institucionalizó la actividad y los sujetos de ésta se convirtieron en titulares de la actividad y por tanto, pueden delegarla a su vez. Con otras palabras, no habría ya diferencia alguna entre provincias senatoriales y provincias imperiales, pero lo cierto es que sí había diferencias entre ambas, aunque menores: entre otras, el procónsul puede manumitir aunque no haya llegado aún a su provincia, mientras que el legado de Augusto carece de jurisdicción fuera de su provincia, sin duda porque la suya es una jurisdicción delegada. La alternativa es la de Mommsen: los legados dependen directamente del

16 Costabile - Licandro 2000, 52.

17 Fanizza 1994. Su único respaldo es un texto no técnico (Suet., Aug. 33.3): Appellationes quotannis urbanorum quidem litigatorum praetori delegabat urbano, at provincialium consularibus uiris, quos singulos cuiusque provinciae negotiis praeposuisset. 
emperador: el texto de Dión Casio, 53.14.7, mencionado antes, dice que los legados los eligen los gobernadores, aunque contando con la aprobación del emperador, si bien va referido a las provincias llamadas del pueblo y el Senado, pero ya hemos visto que en este punto había coincidencias entre ambas clases de provincias. Por tanto, son legados del propio emperador, aunque subordinados al gobernador provincial, como quiere Estrabón, 3.4.20. Esto no convierte, pace Alföldy, a Lucio Sestio Quirinal en un legado del emperador subordinado al gobernador de la Hispania Citerior, porque el lenguaje que emplea el bronce de El Bierzo es suficientemente explícito: leg(ato) meo eam provinciam optinente $\{m\}$.

\section{Las fronteras de la Transduriana}

En el año 2000, acepté, aunque con dudas, la idea tradicional que considera que $A s-$ turia et Gallaecia estuvieron durante un tiempo integradas en la Lusitania. Esta idea se apoya en dos argumentos: por un lado, un pasaje de Plinio el Viejo (4.118) que muestra que en el Orbis pictus de Agripa se daban las medidas (longitudo et latitudo) de Lusitania cum Asturia et Gallaecia. ${ }^{18}$ Como ya señalé en su momento, este argumento es frágil porque, como vemos en Plinio, con frecuencia las medidas del Orbis pictus no estaban referidas a provincias. Por tanto, el testimonio del Orbis pictus no es concluyente. El segundo argumento es el pasaje de Estrabón (3.4.20) en el que se dice que quienes viven al norte del Duero eran llamado antes lusitanos, pero hoy galaicos. En este caso, el problema es pensar en provincias cuando está claro que Estrabón emplea denominaciones étnicas, no administrativas. A mi juicio, con "antes", Estrabón se está refiriendo a geógrafos anteriores a él, como Posidonio, según apunta Jean-Michel Roddaz ${ }^{19}$ o tal vez Artemidoro. En P. Artemid. IV, 1-14, leemos:

"Desde los montes Pirineos hasta la región de Gadira y las zonas más interiores, todo el territorio está llamado indistintamente Iberia e Hispania. Ha sido dividido por los romanos en dos provincias. Forma parte de la primera provincia todas la región que se extiende desde los montes Pirineos hasta la Nueva Cartago, Kastolôn y las fuentes del Betis; forman parte de la otra provincia los territorios que llegan hasta Gadeira y toda la extensión de la Lusitania". ${ }^{20}$

Como señala el propio Moret: "se dio el nombre de Lusitani, indistintamente a los adversarios a los que se enfrentaban los gobernadores de la Ulterior mientras progresaban hacia el noroeste de la Península". ${ }^{21}$ Evidentemente, cuando escribe Artemidoro, la Lusitania en sentido lato llegaba hasta el golfo ártabro, pero esto no se refiere a la provincia Lusitania que creó más tarde Augusto. Por tanto, Gallaecia y Asturia for-

18 No es relevante en este sentido Plinio, NH 33.78 donde se lee que Asturia, Callaecia y Lusitania producían 20.000 libras de oro al año, pues no cabe inferir de ahí que en algún momento Asturia y Callaecia estuviesen integradas en la Lusitania.

19 RodDAz 2007, 22.

20 Traducción de Moret 2012, 431.

21 Moret 2012, 444. 
maban parte de esa Lusitania en sentido lato, geográfico, pero, como ha sugerido Jean Michel Roddaz, nunca pertenecieron a la provincia de ese nombre. Esto simplifica notablemente los cambios en la división provincial durante el reinado de Augusto.

La frontera sur de la Transduriana, evidentemente, no plantea problemas, pero es mucho más difícil determinar sus límites por el Este. ${ }^{22}$ Apoyándose en Estrabón 3.4.20, Costabile y Licandro consideran que el territorio del primer legado (presbeutés) coincidía con el de la ya extinta provincia Transduriana y que por tanto ésta abarcaba el territorio de los astures y los cántabros. ${ }^{23}$ Por mi parte, puse el límite en la misteriosa Noega, todavía no localizada aunque se supone que estaba en la desembocadura del Sella. ${ }^{24}$ La menciona Estrabón, 3.4.20, como límite entre astures y cántabros; también lo hace la divisio orbis terrarum, e igualmente Plinio, 4.111, en la regio Asturum (señalando que a continuación está el conventus Lucensis) y Pomponio Mela (entre los astures, 3.13) y Tolomeo (2.3.6: Noega Ocesia). ${ }^{25}$ Sigo creyendo que tanta presencia e importancia se debe a su efímera posición dentro de la provincia Transduriana y por tanto, que Noega marcaba el límite y la Transduriana no incluía territorio cántabro ni coincidía exactamente con el territorio del primer legado en Estrabón, 3.4.20.

\section{Bibliografía}

Abascal, J. M. (2006): "Los tres viajes de Augusto a Hispania y su relación con la promoción jurídica de ciudades" Iberia 9, 63-78.

Albertini, E. (1923): Les divisions administratives de l'Espagne romaine, Paris.

ALFÖLDY, G.

(1969): Fasti Hispanienses. Senatorische Reichsbeamte und Offiziere in den spanischen Provinzen des römischen Reiches von Augustus bis Diokletian, Wiesbaden.

(2000): Provincia Hispania Superior, Heidelberg.

(2000a): "Das neue Edikt des Augustus aus El Bierzo in Hispanien", ZPE 131, 177-205. (2007): "Fasti und Verwaltung der hispanischen Provinzen: zum heutigen Stand der Forschung", [en] R. Haensch y J. Heinrich, (eds.), Herrschen und Verwalten: Der Alltag der römischen Administration in der Hohen Kaiserzeit, Colonia, 325-356.

(2011): "Tausend Jahre Epigraphischen Kultur im römischen Hispanien", Lucentum $30,187-220$.

Cortijo Cerezo, M. L. (1992): "Sobre la delimitación de la Bética como provincia", [en] In memoriam J. Cabrera Moreno, Granada, 51-68.

Costabile, F. - Licandro, O. (2000): Tessera Paemeiobrigensis. Un nuovo editto di Augusto dalla Transduriana provincia e l'imperium proconsulare del Princeps, Roma.

Crawford, M. (1996): Roman Statuses, London. 2012.

22 Sobre la gran importancia de los ríos como límites provinciales, cfr. Cortijo Cerezo 1992 y PurCELL

23 COSTABile - Licandro 2000, 55.

24 LÓPEz BARJA 2000.

25 Sobre las distintas propuestas de localización que se han hecho, véase GARCía AlONSO 2003, 156. 
Diego Santos, F. (2002): "La provincia Transduriana y la provincia Hispania Nova Citerior Antoniniana" Boletín del Real Instituto de Estudios Asturianos 159, 249-263.

D’Ors, A. (1953): Epigrafía jurídica de la España romana, Madrid.

FANIZZA, L. (1994): “Iurisdictio mandata”, SDHI 60, 303-359.

Ferrary, J.-L. (2001): “À propos des pouvoirs d'Auguste” Cahiers du Centre Gustave Glotz $12,101-154$.

García Alonso, J. L. (2003): La Península Ibérica en la Geografía de Claudio Ptolomeo, Vitoria.

García RiazA, E. (2011): “Derecho de guerra en Occidente durante la expansión romanorepublicana. Planteamientos metodológicos”, [en] E. García Riaza, (ed.), De fronteras a provincia. Interacción e integración en Occidente, Palma de Mallorca, 31-65.

GrÜNER, A. (2005): “Die Ältare des L. Sestius Quirinalis bei Kap Finisterre. Zur geopolitischen Konstruktion des römischen Herrschaftsraums”, Madrider Mitteilungen 46, 247-266.

Hardy, E. G. (1912): Roman Laws and Charters, Oxford.

Henderson, M. (1942): “Julius Caesar and Latium in Spain”, JRS 32, 1-13.

Косн, М. (1989): “Ein neuer Beamtenname aus dem republikanischen Hispanien”, Chiron 19, 27-35.

Mommsen, Th. (1905): “Lex Coloniae Iuliae Genetiuae siue Vrsonensis”, Ephemeris Epigraphica 2, 108-151 (= Gesammelte Schriften I, Berlín, 194-264).

Moret, P. (2012): “Artemidoro y la ordenación territorial de Hispania en época republicana”, [en] J. Santos - G. Cruz Andreotti, (eds.), Romanización, fronteras y etnias en la Roma antigua: el caso hispano, Vitoria, 425-456.

Palao, J. J. (2012): "El ejército romano y la ordenación del territorio en Hispania", [en] J. Santos - G. Cruz Andreotti (eds.), Romanización, fronteras y etnias en la Roma antigua: el caso hispano, Vitoria, 83-112.

Purcell, N. (2012): "Rivers and the Geography of Power", Pallas 90, 373-387.

RICHARDSON, J. (2008): The Language of Empire. Rome and the Idea of Empire from the Third Century B.C. to the Second Century A.D., Cambridge.

RodDAz, J.-M. (2007): “Le Douro: ligne de frontière ou ligne de contact?”, [en] M. Navarro Caballero - J. J. Palao Vicente (eds.), Villes et territoires dans le bassin du Douro à l'époque romaine, Bordeaux, 15-25.

SyME, R.

(1969): “A Governor of Tarraconensis", Epigraphische Studien 8, 125-133 (= Roman Papers, vol. II, Oxford, 1979, 732-741).

(1970): “The Conquest of North-West Spain", [en] Legio VII Gemina, León, 83-107 (= Roman Papers, Oxford, 1979, 825-854). 